\title{
布の風合い評価における触·視覚の相互関係
}

\author{
共立女子大学家政学部 小林 茂雄・富塚 美恵

\section{INTERRELATION OF TACTILE AND VISUAL SENSES ON ASSESSMENT OF FABRIC HAND}

\section{By Shigeo Kobayashi and Mie Tomizuka}

Faculty of Home Economics, Kyoritsu Women's University, Hitotsubashi, Chiyoda-ku, Tokyo, 101 Japan

\begin{abstract}
The effect of tactile and visual senses on assessments of fabric hand is discussed. Twenty-five samples were collected from the point of view of the hand of fiber materials, such as silk--, wool-, cotton-, linen- and leather-like hand. Sensory qualities of these samples were rated by touch, by sight, and by both senses together. The results of judgements of SD method and similar rating method were analyzed by using factor analysis. Main conclusions were as follows. From the results of factor analysis of SD method, three factors, namely bulkiness, smoothness and stiffness, and liveliness (koshi) were obtained in the case of tactile assessment. On the other hand, same two factors, namely bulkiness, and smoothness and stiffness were obtained in the case of visual and tactivisual assessments. Furthermore, the factor structure between visual and tactivisual assessments was very similar in the point of factor lodings and contribu. tions. From the result of similar rating method, the graph of subjective similarity on visual and tactivisual assessments showed a very similar tendency. Five fundamental factors were obtained by the factor analysis, but the wool-like hand was included in the silk-like factor as unsilky images. These factors were silk-, cotton-, linen-, suede- and leather-like hand. It became clear that the tactivisual assessment of fabric hand is influenced considerably by the sense of sight.
\end{abstract}

(Received December 27, 1989)

\section{1. 緒言}

布の風合いは布の力学的特性を, 主に触覚により官能 的にとらえたものであると考えている場合が多い。しか しながら，実際に風合いを評価する祭には，視覚が関与 した状態で評価が行われている。従って，風合いを主に 触覚による評価量としても，そこには当然視感が影響す ることが考えられる。

風合い評価における触覚と視覚の関係については, 古 くはBinns 以来， $2 ， 3$ の研究者により検討されてい る。すなわち, Binns ${ }^{1 /}$ は羊毛の品質評価に関する一連 の研究のなかで, 触覚と梘賞の評価に関して評価の一致 度を調ベ，視觉の方が触賞よりも一致度が高いことを明 らかにしている。また, Brown'2)はニット布のバルキー 性に関して触覚と視覚の影響を検討し，視・触覚併用の
評価では触覚よりも視覚に影響されると報告している。 さらに，西松ら゙はパイル織物の風合い栗価に関して， 触覚と視覚の影響につき消費者と専門家の 2 グループを 用いて調べている。その結果では, 視・触覚併用の評価 の場合に，視覚の触覚に対する傮位性が存在し，視覚情 報である表面色の影響を受けると報告している。

これらの報告のように通常行っている視・触覚による 風合い評価が、視覚に影響されることになると，布の風 合い特性について特に視覚的な面からの検討が一層必要 であ。

本研究では風合いを素材別の面からとらえ，素材別の 風合いの基本をなすと考えられる風合い，すなわち，絹 様，羊毛様，木綿様，麻様，皮革様の各風合いの代表的 な素材を用いて，風合い評価における触覚と視覚の相互 関係について検討した。この場合，官能検査には視覚の 
影響を除き触覚のみによる判定, 視覚のみによる判定, 視覚と触覚の併用による判定の 3 方法を用い, 評洒デー 夕に因子分析法を適用し，風合い評価の際の触覚と視覚 の影響について考察した。

\section{2. 試料および実跧方法}

\section{1 試 料}

試料には綃系統 3 種類，毛系統 5 種類，綿柔統 5 種 類，麻系㓍 4 種類，化縺系統 8 種類(人工皮革 4 種類を 含を)の合計25種類を用いた。これらの試料の概要は表 にに示す通りであり，人工皮革を除いて織物である。な お，色はグレー柔执よびブラウン系であり，評価の際の 色の影響について検討するために, 日本電色工業製の測 色色差計 $(Z-\Sigma 80$ 型)により，色相，明度，彩度を測定 し、マンセル表示方法で示した。

\section{2 実烁方法}

風合いの官能検查は, 触覚のみ, 視覚のみ, 視・触覚 の併用の 3 方法により行った。この場合, 触敩のみの判 定の際に視覚の影響を除くために，仕切り板を有する触
覚評価装置を作り実験に用いた。この菨置には手を入れ ることができる大きさの空 2 個があけてあり，この究に 両手を入れて仕切り板の反对側の試料を自由にさわるこ とができる。なお、視賞のみ、および梘・触觉碰用の官 能検查は，北管の自然昼光下で行った。

官能唡査に用いた試料の大きさは夕テ30 $\mathrm{cm} \times \exists コ$ $30 \mathrm{~cm}$ であり, 触觉の判定の際に布を乎で握る動作をし ない上うに指示したはかは，判定方法に制限を与えなか った。また，評洒方法にはSD 評定法と類似度評定法を 用いた。すなわち，SD評定法では触覚のみの場合には 11形容語対，視觉のみの場合，扝よび視・触覚併用の場 合には11形容語対を含む20形容語対を用い，5段階尺度 (非常に，やや，どちらともいえない，やや，非常に）に より判定させた(表 2 参照)。一方，類似度評定法では絹 様, 羊毛様, 木綿椂, 麻様, 皮革様( スエード調，レ开 一調)の風合いに対する類似度を，5段階尺度(非常汇似 ている，ゃや似ている，どちらともいえない，直まり似 ていない，非常に似ていない)により判定させた。な お，宴能検查は $\mathrm{SD}$ 評定法について，触覚のみ，視賞の

Table 1 Samples

\begin{tabular}{|c|c|c|c|c|c|}
\hline & Fiber, Weave, etc. & $\begin{array}{c}\text { Weight } \\
\mathrm{g} / \mathrm{cm}^{2} \times 10^{-2}\end{array}$ & $\begin{array}{l}\text { Thickness } \\
\mathrm{cm} \times 10^{-1}\end{array}$ & & $\begin{array}{l}\text { color } \\
\text { IV/C }\end{array}$ \\
\hline A & Wool $100 \%$, Plain, Flannel, Raising & 2.65 & 1.05 & $4.44 Y$ & $4.98 / 0.20$ \\
\hline $\mathrm{B}$ & Wool $80 \%$ Nylon $20 \%$, Herringbone, Twill, Raising & 3.07 & 1.62 & $7.28 \mathrm{YR}$ & $5.67 / 2.13$ \\
\hline $\mathrm{C}$ & Wool $95 \%$ Nylon $5 \%$, Twill, Raising & 3.38 & 1.79 & $0.86 \mathrm{Y}$ & $6.58 / 1.12$ \\
\hline $\mathrm{D}$ & Wool 100\%, Twill, Serge & 3.05 & 0.73 & $9.66 \mathrm{YR}$ & $8.73 / 0.54$ \\
\hline$E$ & Wool $100 \%$, Plain derivative, Georgette & 2.27 & 0.70 & $3.61 \mathrm{~PB}$ & $4.50 / 2.21$ \\
\hline $\mathrm{F}$ & Cotton $100 \%$, Plain, Broadcloth & 1.23 & 0.27 & $0.78 \mathrm{~PB}$ & $4.34 / 0.91$ \\
\hline G & Cotton $100 \%$, Terry pile, Towet & 1.79 & 1.13 & $2.67 \mathrm{Y}$ & $8.03 / 1.04$ \\
\hline $\mathrm{H}$ & Cotton $100 \%$, Twill, Denim & 3.44 & 0.72 & $3.55 \mathrm{~PB}$ & $2.60 / 3.00$ \\
\hline 1 & Cotton $100 \%$, Twill & 2.29 & 0.45 & $5.61 Y R$ & $4.63 / 6.83$ \\
\hline $\mathrm{J}$ & Cotton $100 \%$, Twill, Soft-denim & 2.43 & 0.65 & $0.70 \mathrm{~PB}$ & $4.02 / 4.32$ \\
\hline $\mathrm{K}$ & Linen $100 \%$, Twill & 1.50 & 0.31 & $1.15 Y R$ & $4.36 / 6.83$ \\
\hline L & Linen $100 \%$, Plain & 1.15 & 0.25 & $4.87 \mathrm{YR}$ & $5.68 / 3.52$ \\
\hline M & Linen $30 \%$ Polyester $70 \%$, Plain & 1.82 & 0.56 & $9.10 \mathrm{YR}$ & $7.23 / 1.37$ \\
\hline$N$ & Linen $25 \%$ Polyester $75 \%$. Plain & 2.02 & 0.56 & $8.46 \mathrm{YR}$ & $6.70 / 2.15$ \\
\hline $\mathrm{O}$ & Silk $100 \%$, Plain, Habutae & 0.64 & 0.16 & $0.30 \mathrm{Y}$ & $7.41 / 1.60$ \\
\hline $\mathrm{P}$ & Silk $100 \%$, Plain, Habutae & 0.60 & 0.14 & $4.58 \mathrm{YR}$ & $7.64 / 2.40$ \\
\hline$Q$ & Silk $100 \%$, Plain, Burberry & 1.36 & 0.27 & $7.56 \mathrm{YR}$ & $5.01 / 2.94$ \\
\hline $\mathrm{R}$ & Cupra $100 \%$, Plain, Lining & 0.68 & 0.10 & $9.86 \mathrm{~B}$ & $5.52 / 0.74$ \\
\hline$S$ & Polyester $100 \%$, Satin & 0.98 & 0.23 & $7.90 \mathrm{YR}$ & $7.79 / 2.19$ \\
\hline $\mathrm{T}$ & Polyester $100 \%$. Plain derivative, Georgette & 0.64 & 0.19 & $1.63 \mathrm{~PB}$ & $5.24 / 3.65$ \\
\hline $\mathrm{U}$ & Rayon $100 \%$, Pile, Velvet & 2.54 & 1.48 & $7.43 \mathrm{YR}$ & $4.24 / 1.32$ \\
\hline $\mathrm{V}$ & Man-made leather, Leather-like & 2.03 & 0.55 & $5.89 \mathrm{YR}$ & $5.25 / 0.32$ \\
\hline W & Man-made leather, Suede-like & 2.35 & 0.75 & $0.55 \mathrm{~PB}$ & $5.12 / 2.28$ \\
\hline $\mathrm{X}$ & Man-made leather. Suede-like & 2.20 & 0.66 & $0.63 \mathrm{~PB}$ & $4.74 / 2.18$ \\
\hline$Y$ & Man-made leather, Suede-like & 2.85 & 0.97 & $2.03 \mathrm{YR}$ & $4.96 / 3.76$ \\
\hline
\end{tabular}


Table 2 Polar-pair Adjective Words Used for Hand Evaluations

\begin{tabular}{|c|c|c|c|}
\hline & $\begin{array}{l}\text { very } \quad \text { slightly } \\
\end{array}$ & $\begin{array}{l}\text { neutral slightly } \\
\end{array}$ & very \\
\hline (1) rough & & & smooth \\
\hline (2) $\mathrm{cool}$ & & & warm \\
\hline (3) bulky & & & sleazy \\
\hline (4) heavy & & & light \\
\hline (5) springy & & & non-springy \\
\hline (6) pliable & & & stiff \\
\hline (7) dry & & & damp \\
\hline (8) hard & & & soft \\
\hline (9) thin & & & thick \\
\hline (10) fuzzy & & & clean \\
\hline (ii) lively & & & limp \\
\hline (19) light & & & dark \\
\hline (13) homely & & & smart \\
\hline (14) lustrous & & & lusterless \\
\hline (15) rich & & & poor \\
\hline (16) dirty & & & beautiful \\
\hline (12) superficial & & & deep \\
\hline (11) active & & & delicate \\
\hline (19) superior & & & inferior \\
\hline (20) like & & & dislike \\
\hline
\end{tabular}

み，視・触覚併用の順序で行った。類似度評定法による 官能唡查は，SD 評定法の後で日を改めて同じ順序で行 った。これらの官能検查では，試料の提示順序の影響を 除くために，人ごとに提示順序をランダム化した。

官能検査に用いた被験者は被服学科の大学 $3 ， 4$ 年 生, および大学院生の女子学生20名である。

\section{3. 結果および考察}

\subsection{SD 評定法による検討}

触覚のみ，視覚のみ，視・触覚併用の 3 方法による SD 評定結果について，被験者 20 人の評定デー夕を検討 したが，評価には多少のバラツキがあるものの，明らか に異なった評価の反応を示した被験者はいなかった。そ こで $\mathrm{SD}$ 評定のデータとして，20人の被験者の平均值を 用いた。ただし，SD 法の5段階尺度には左側から順 に，非常に(1点)，やや(2点)，どちらともいえない ( 3 点)，やや( 4 点)，非常に( 5 点) 女与えて数值化した (表 2 参照)。

触覚のみ，視覚のみ，視・触覚併用の 3 万法につい て，因子分析法を適用し評価の因子構造を調べた。すな わち， 3 方法に共通している11形容語対の SD 評定デー 夕の平均値を用い，相関係数行列を算出し因子分析(主 因子法, バリマックス回転)により基本因子を抽出し た。また，視覚のみ，視・触喾併用の 2 方法について は，20形容語対の平均値を用い，同様の方法により基本 因子を抽出した。なお，各因子分析において，因子の抽 出基準は固有値1.0以上とした。

表 3 は11形容語对による因子分析の結果である。因子 負荷量の大きさをもとに，抽出された各因子の意味を考 察する。触覚のみの場合には，第1因子では暖かい，ふ っくらした，重い，弾力性のある，しっとりした，厚 い，毛羽立ったの因子負荷量が大きい。これらの形容語 の共通性を総合的に考慮し，かさ高性の因子とした。以 下，因子負荷量の大きさに注目しながら，第 2 因子は平 滑性と剛軟性，第 3 因子は腰を表す因子とした。また，

Table 3 Factor Loading (Case of 11 Words)

\begin{tabular}{lrrrrrrr}
\hline \multirow{2}{*}{ Word } & \multicolumn{3}{c}{ Factor (Tactual) } & \multicolumn{2}{c}{ (Visual) } & \multicolumn{2}{c}{ (Tactivisual) } \\
\cline { 2 - 8 } & \multicolumn{1}{c}{1} & \multicolumn{1}{c}{2} & \multicolumn{1}{c}{3} & \multicolumn{1}{c}{1} & 2 & 1 & 2 \\
\hline (1) rough & 0.155 & 0.937 & -0.211 & 0.255 & 0.833 & 0.144 & 0.881 \\
(2) cool & -0.927 & -0.090 & -0.323 & -0.973 & 0.007 & -0.967 & 0.077 \\
(3) bulky & 0.874 & 0.340 & 0.267 & 0.937 & 0.177 & 0.983 & 0.051 \\
(4) heavy & 0.867 & 0.064 & -0.398 & 0.836 & 0.383 & 0.841 & 0.296 \\
(5) springy & 0.931 & -0.109 & 0.127 & 0.976 & -0.007 & 0.944 & -0.106 \\
(6) pliable & -0.052 & -0.870 & 0.471 & -0.220 & -0.950 & -0.079 & -0.959 \\
(7) dry & -0.862 & 0.419 & 0.095 & -0.833 & 0.157 & -0.797 & 0.406 \\
(8) hard & -0.197 & 0.564 & -0.791 & -0.181 & 0.968 & -0.372 & 0.789 \\
(9) thin & -0.925 & -0.225 & 0.248 & -0.886 & -0.407 & -0.906 & -0.319 \\
(10) fuzzy & 0.815 & 0.530 & 0.129 & 0.934 & 0.181 & 0.906 & 0.235 \\
(1) lively & -0.034 & -0.213 & 0.963 & -0.101 & -0.856 & -0.198 & -0.636 \\
\hline Contribution(\%) & 50.65 & 24.04 & 20.52 & 54.27 & 33.32 & 53.50 & 28.65 \\
\hline
\end{tabular}


Table 4 Factor Loading (Case of 20 Words)

\begin{tabular}{lrrrrrr}
\hline & \multicolumn{3}{c}{ Factor (Visiual) } & \multicolumn{3}{c}{ Factor (Tactivisual) } \\
\cline { 2 - 7 } & \multicolumn{1}{c}{ Word } & \multicolumn{1}{c}{ 1 } & \multicolumn{1}{c}{3} & \multicolumn{1}{c}{1} & \multicolumn{1}{c}{3} \\
\hline (1) rough & 0.907 & -0.187 & -0.080 & 0.905 & -0.096 & -0.092 \\
(2) cool & -0.121 & 0.963 & -0.143 & -0.100 & 0.971 & -0.140 \\
(3) bulky & 0.346 & -0.910 & 0.137 & 0.221 & -0.922 & 0.154 \\
(4) heavy & 0.184 & -0.852 & -0.420 & 0.171 & -0.822 & -0.462 \\
(5) springy & 0.105 & -0.952 & 0.060 & -0.088 & -0.943 & -0.037 \\
(6) pliable & -0.845 & 0.201 & 0.377 & -0.831 & 0.013 & 0.390 \\
(7) dry & 0.307 & 0.855 & 0.236 & 0.409 & 0.812 & 0.087 \\
(8) hard & 0.697 & 0.174 & -0.554 & 0.526 & 0.424 & -0.550 \\
(9) thin & -0.300 & 0.885 & 0.300 & -0.283 & 0.869 & 0.325 \\
(10) fuzzy & 0.357 & -0.903 & 0.133 & 0.382 & -0.890 & 0.096 \\
(11) lively & -0.437 & 0.121 & 0.802 & -0.449 & 0.100 & 0.832 \\
(12) light. & -0.387 & 0.052 & 0.683 & -0.396 & 0.207 & 0.691 \\
(13) homely & 0.939 & -0.173 & -0.068 & 0.925 & -0.161 & -0.063 \\
(14) lustrous & -0.729 & 0.560 & 0.261 & -0.741 & 0.537 & 0.284 \\
(15) rich & -0.557 & -0.773 & 0.140 & -0.562 & -0.732 & 0.049 \\
(16) dirty & 0.869 & -0.109 & -0.371 & 0.863 & -0.073 & -0.362 \\
(17) superficial & -0.002 & 0.975 & 0.101 & -0.005 & 0.901 & 0.112 \\
(18) active & 0.873 & -0.303 & -0.289 & 0.890 & -0.179 & -0.369 \\
(19) superior & -0.907 & -0.141 & 0.218 & -0.905 & -0.155 & 0.248 \\
(20) like & -0.579 & -0.464 & 0.452 & -0.597 & -0.456 & 0.459 \\
\hline Contribution(\%) & 36.25 & 40.37 & 12.63 & 35.33 & 38.68 & 13.26 \\
\hline
\end{tabular}

視覚のみの場合には，第 1 因子はかさ高性、第 2 因子沖 平滑性と剛軟性を表す因子と考えられ，視・触覚併用の 場合の第 1 因子扰よび第 2 因子は，視覚のみの場合の因 子と同じ意味である。

この 3 つの因子構造の違いは, 触覚のみの場合には, かさ高性，平滑性之剛軟性，腰の 3 因子構造をとるのに 対して，視覚のみの場合および視・触覚併用の場合に は，加高性，平滑性と剛軟性の 2 因子構造をとり，触 賞のみの場合に抽出された腰の因子が第 2 因子に包含さ れていることである。このように視覚のみと視・触覚併 用の因子構造が, 抽出因子数, 各形容語の因子負荷量, 因子寄与率の面からほほ同じ構造をなし，触覚のみの場 合の因子構造と異なる。このことは視・触覚併用の評価 が，視覚のみの評価に大きく依存していることを示して いる。

表 4 は20形容語対による視覚のみ，視・触覚併用の 2 つの場合の因子分析の結果である。各因子の意味を考察 すると，視喾のみ，視・螌覚併用の両者の場合とも，第 1 因子は平滑性と馉軟性, 第 2 因子はかさ高性, 第 3 因 子は腰を表わす因子と考文られ，抽出因子数，各形容語 の因子負荷量, 因子寄与率の面加 2 つの因子分析の因 子構造がほぼ同じ構造を有する。このことは表 3 の分析
と同様に，視・触覚併用の評価が，視覚の評価に大きく 依存していることを示している。

さて，本実験では試料の項で前述したように，試料の 色が同色に統一されているわけではない。すなわち、ク レー系とブラウン系とあるために，視覚の評価では色の 要因が影響することが考えられる。そこで，SD評定に 対する色の要因の影锌について検討した。

触覚の評価に用いた11形容語対のうち，色の要因の影 響を特に受けると考えられるものとして，冷たいい暖 かい，重いい軽い，硬いい柔らかいの 3 形容語对を選 びだした。また，色の要因として色相，明度，彩度の3 属性について，測色色差計の測定值をもとに㛟討した。 その結果，彩度は試料間にあまり大きな差がみられない ため，色相と明度について検討することにした。

前述の表 1 に示したマンセル值(HV/C)をもとに, 色 相についてはグレー采とブラウン系の 2 グルーフに，ま た，明度については7.0以上と5.0以下の2グルーフト分 けた(表 5 参照)。これらの各グルーブごとに，SD評定 の平均值を求めると表 6 のようになる。

表加触覚のみと梘覚のみの2つの場合について，色 相のグレー系・ブラウン系の間，および明度の高・低の 間で，平均評点の大小関係を検討した。その結果では各 
Table 5 Groups of Samples by Hue and Value

\begin{tabular}{lll}
\hline \multirow{2}{*}{ Hue } & Grey group & E, F, H, J, R, T, W, X \\
\cline { 2 - 3 } Brown group & $\begin{array}{l}\text { B, C, D, G, I, K, L, M, N, O, P, Q, } \\
\text { S, U, V, Y }\end{array}$ \\
\hline Value & High group & D, G, I, M, O, P, S \\
\cline { 2 - 3 } & Low group & A, E, F, H, J, K, U, X, Y \\
\hline
\end{tabular}

形容語対に関して，グレー系とブラウン系で触覚のみと 視覚のみの間で平均点には多少の差があるが，大小関係 は一致している。このことは明度の高・低の場合につい てもいえる。このように大小関係が触覚のみと，視覚の みの場合で一致することから、今回用いた試料の範用で は，色相および明度の影響は小さいと考えられる。

\section{2 類似度評定法による検討}

触覚のみ，視覚のみ，視・触覚併用の3方法につい

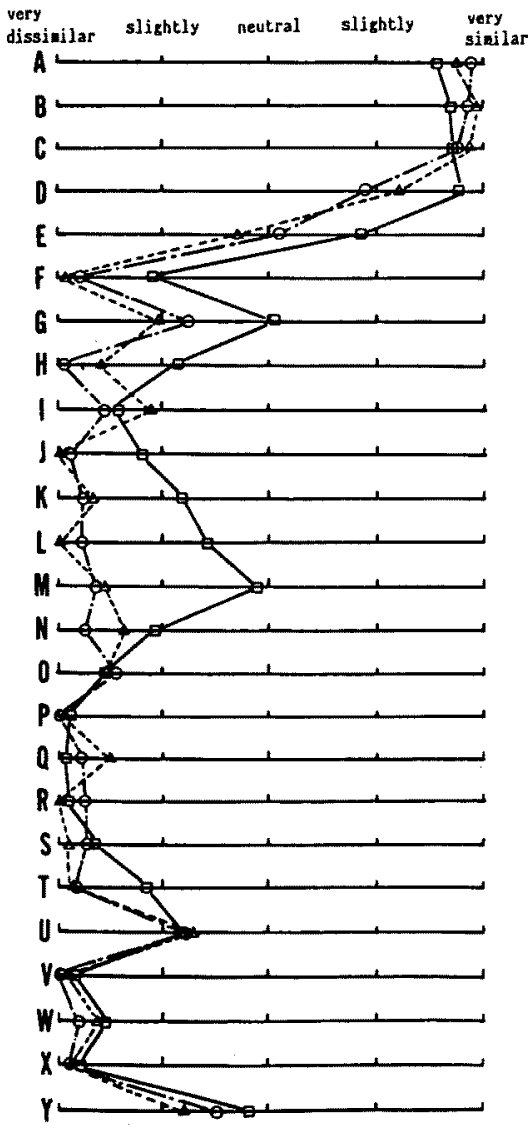

Fig. 1. Similar rating graph (Wool-like hand) $-\square$ - tactual $\cdots \Delta \cdots$ visual $-\mathrm{O}$ - tactivisual $A \sim E$ wool type, $F \sim J$ cotton type, $K \sim N$ linen type, $O-$ $\mathrm{Q}$ silk type, $\mathrm{R} \sim \mathrm{U}$ man-made fiber type, $\mathrm{V} \sim \mathrm{Y}$ man-made leather type.
Table 6 Mean Scores of SD Method

\begin{tabular}{|c|c|c|c|c|}
\hline \multirow{3}{*}{$\begin{array}{r}\text { Adjective } \\
\text { word }\end{array}$} & Tactual & Visual & Tactual & Visual \\
\hline & \multicolumn{2}{|c|}{ Hue } & \multicolumn{2}{|c|}{ Value } \\
\hline & Grey Brown & Grey Brown & High Low & High Low \\
\hline $\mathrm{cool} \hookleftarrow$ warm & $3.39>3.09$ & $3.23>2.95$ & $3.20<3.59$ & $2.96<3.44$ \\
\hline heavy $\longrightarrow$ light & $3.49>3.44$ & $3.44>3.21$ & $3.70>3.09$ & $3.91>2.81$ \\
\hline hard $\hookrightarrow$ soft & $3.68>3.36$ & $3.36>3.24$ & $3.60>3.26$ & $3.56>3.11$ \\
\hline
\end{tabular}

て，絹様，羊毛様，木綿様，麻様，皮革様(スエード 調，レザー䛿)の風合いにどの程度似ているかを 5 段階 尺度で評価させ，20人の被驗者の平均評点を求めた。な お，5段階尺度には非常に似ている(5点)，やや似てい る(4 点), どちらともいえない( 3 点)，あまり似ていな い(2点), 非常に似ていない(1 点)を与えて数值化し た。

図 1一図 3 は触覚のみ，視覚のみ，視・触覚併用の3 者間で比較的差のでた場合につき，類似度プロフィール を示したものである。図から明らかなように, 視・触覚

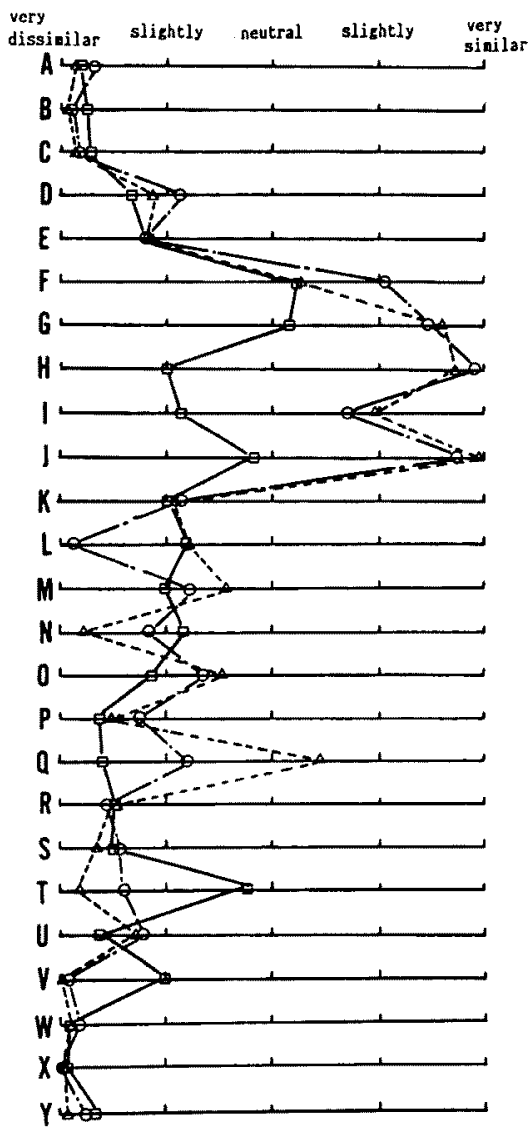

Fig. 2. Similar rating graph (Cotton-like hand). 


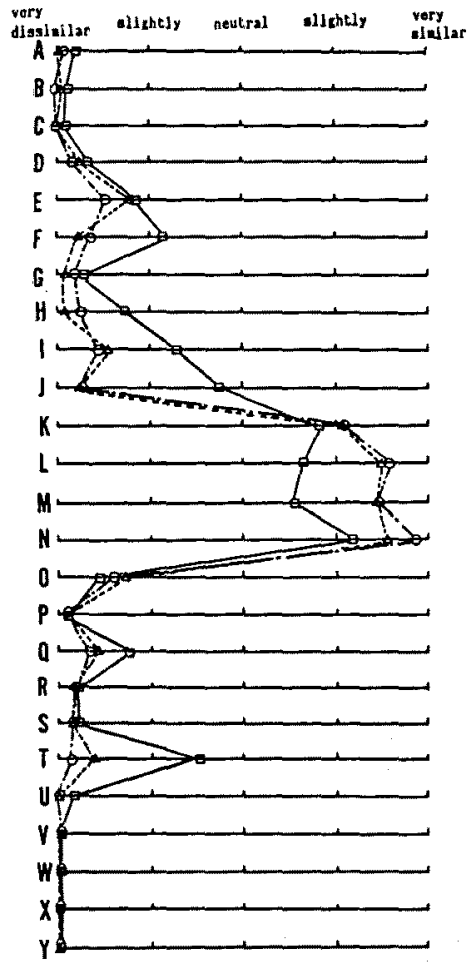

Fig. 3. Similar rating graph (Linen-like hand).
研用のプロフィールと視覚のみのプロフィール仗全体的 に似ているのに対して，触覚のみのプロフィールは異な っているものが多く見られる。特に図 2 において，綿蟣 物の木綿様质合いへの類似度評定では，触覚のみの評定 が他の 2 者の評定と大きく異なっている。これらの類似 度プロフィールの傾问から, 視・触覚併用の俨価が触賞 よりも視覚により影響されるものと考えられる。

次に類似度の平均評点をもとに，因子分析(主因子 法，バリマックス回転)を行い素材別の風合いの因子擭 造を調べた。なお，因子の抽出基準は固有値1.0以上と した。

表 7 は因子分析の結果であり，第 5 因子までの累積因 子奇与率は93.8\%に達する。因子負荷量加ら各因子の意 昧を考察すると、第 1 因子は皮革様(レザー調)，第 2 因 子は絹様，第 3 因子は木綿様，第 4 因子は麻様，第 5 因 子は皮革様(スエード調)を表わす因子であり、各因子は 因子真荷量の大きさからみて明暸に特徵づけられてい る。なだし，羊毛様は絹様の逆，すなわち，絠らしくな いの意味として第2 2 因子に包含されて抽出された。

\section{4. 結論}

絹様，羊毛様，木綿様，糜様，皮革様(レザ一調およ びスエード調)の素材別試料を用いて，SD評定法と類似

Table 7 Factor Loadings

\begin{tabular}{|c|c|c|c|c|c|}
\hline \multirow{2}{*}{ Hand } & \multicolumn{5}{|c|}{ Factor } \\
\hline & 1 & 2 & 3 & 4 & 5 \\
\hline Silk-like $(T)$ & -0.235 & 0.887 & 0.173 & -0.158 & 0.288 \\
\hline Wool-like $(T)$ & -0.411 & -0.738 & 0.339 & -0.030 & 0.221 \\
\hline Linen-like $(T)$ & -0.146 & -0.054 & -0.328 & 0.788 & 0.212 \\
\hline Cotton-like ( $\mathrm{T}$ ) & -0.020 & 0.051 & -0.770 & 0.118 & 0.328 \\
\hline Suede-like $(\mathrm{T})$ & 0.086 & -0.162 & 0.179 & -0.215 & -0.920 \\
\hline Leather-like (T) & 0.943 & -0.090 & 0.044 & -0.132 & -0.141 \\
\hline Silk-like (V) & -0.208 & 0.881 & 0.240 & -0.092 & 0.307 \\
\hline Wool-like (V) & -0.294 & -0.731 & 0.402 & -0.373 & 0.196 \\
\hline Linen-like (V) & -0.129 & -0.011 & 0.094 & 0.962 & 0.163 \\
\hline Cotton-like (V) & -0.122 & -0.069 & -0.918 & 0.018 & 0.129 \\
\hline Suede-like (V) & 0.219 & -0.056 & 0.206 & -0.167 & -0.924 \\
\hline Leather-like (V) & 0.953 & -0.020 & 0.148 & -0.128 & -0.107 \\
\hline Silk-like (TV) & -0.235 & 0.872 & 0.256 & -0.192 & 0.260 \\
\hline Wool-like (TV) & -0.316 & -0.715 & 0.425 & -0.380 & 0.207 \\
\hline Linen-like (TV) & -0.122 & -0.025 & 0.052 & 0.961 & 0.167 \\
\hline Cotton-like (TV) & -0.186 & -0.063 & -0.955 & -0.044 & 0.146 \\
\hline Suede-like (TV) & 0.112 & -0.093 & 0.187 & -0.161 & -0.949 \\
\hline Leather-like (TV) & 0.973 & 0.003 & 0.129 & -0.108 & -0.118 \\
\hline Contribution $(\%)$ & 19.02 & 22.09 & 17.92 & 16.59 & 18.14 \\
\hline
\end{tabular}

(T), Tactual: (V), Visual; and (TV), Tactivisual. 
度評定法により，風合い評価に抢ける触覚と視覚の関係 を考察した結果，次のことが明らかになった。

(1) SD 評定法のデータについて因子分析法を適用し, 触 賞のみ, 視覚のみ, 梘・触覚併用の 3 垀価につき因子構 造を険討した。触覚の評価に用いた11形容語対の因子分 析では，触覚のみの場合には，かさ高性，平滑性と剛軟 性, 腰の 3 因子棈造となるのに対して, 視覚のみ, 視 · 触覚併用の両者の場合には, かさ高性, 平滑性と剛軟性 の2因子構造となった。また, 視覚が関与した評洒に用 いた20形容語対の因子分析では, 視覚のみ, 視・触覚併 用の耐者の場合とも，かさ高性，平滑性と剛軟性，腰の 3 因子構造となった。このように抽出因子数とその因子 の意味が, 視覚のみ, 視・触覚併用では一致するばかり でなく，两者は因子負荷量拉よび因子寄与率の点加らも 類似している。これらのことから, 視・触喾併用の評価 は視覚の影響を強く受けると考えられる。
(2)類似度評定法のデータについて平均評点のプロフィー ルおよび因子分析法により，触覚のみ，視覚のみ，梘・ 触賞併用の 3 評価の関係を検討した。視・触覚併用の場 合と視覚のみの場合のプロフィールは類似して㧍り， 視・触喾併用の評価は視覚の影響を強く受计ると考えら れる。また, 因子分析の結果, 綃様, 木綿様, 麻様, 皮 革様(レザー調，スエード調)が特徴的な風合いの因子と して抽出された。しかし，羊毛様は絹様の反対の風合い イメージとして，絹様のなかに包含されて抽出された。

付記：本研究は繊維学会「第 3 回感覚と計測に関する シンポジウム」(1989年6月)において発表した。

\section{文献}

1) H. Binns, J. Text. Inst., 25, T334 (1934)

2) P. Brown, Text. Res. J., 39, 395 (1969)

3 ）西松豊典，酒井哲也，䄉学誌，43，211（1987） 